\title{
Standardization of the methylation-specific PCR method for analyzing BRCA1 and ER methylation
}

\author{
VO THI THUONG LAN ${ }^{1,2}$, NGO THI HA ${ }^{1,3}$, NGUYEN QUYNH UYEN ${ }^{3}$, NGUYEN THI DUONG ${ }^{1}$, \\ NGUYEN THI THU HUONG ${ }^{1,2}$, TA BICH THUAN ${ }^{1,2}$, PHAM ANH THUY DUONG ${ }^{1}$ and TA VAN TO ${ }^{4}$ \\ ${ }^{1}$ Faculty of Biology, ${ }^{2}$ Genomics Unit, Key Laboratory of Enzyme and Protein Technology, Hanoi University of Science, \\ ${ }^{3}$ Institute of Microbiology and Biotechnology, Vietnam National University, ${ }^{4}$ Department of Cytology and Pathology, \\ National Cancer Hospital K, Hanoi, Vietnam
}

Received June 11, 2013; Accepted February 5, 2014

DOI: $10.3892 / \mathrm{mmr} .2014 .1990$

\begin{abstract}
The significant differences in DNA methylation that are considered to be a biomarker for the diagnosis of cancer are a barrier to the application of biomarkers in the clinical field. In the present study, new primers were designed and further standard controls were set up to validate the accuracy of the methylation-specific PCR (MSP), a method widely used to analyze DNA methylation. By analyzing the methylation pattern of breast cancer 1 (BRCAl) and estrogen receptor $(E R)$ in 60 patients with breast cancer, the number of cases of methylated $B R C A 1$ and $E R$ detected by the primer was $7 / 60$ and $21 / 60$, respectively, whereas that detected by the previous widely used primers was $25 / 60$ and $47 / 60$, respectively. Sequencing of the MSP products indicated that the 18 and 26 false-positive methylations of BRCA1 and $E R$, respectively, were due to insufficient validation of the previously used primers. Thus, the present study proposes that all studies based on the MSP approach should incorporate more controls to validate the precision of the MSP primers.
\end{abstract}

\section{Introduction}

The methylation of deoxycytidine nucleotides distributed in $\mathrm{CpG}$ islands is well known as an epigenetic regulation mechanism for genomic function. Alteration of the DNA methylation pattern has been identified to be closely associated with carcinogenesis $(1,2)$. Aberrant DNA hypermethylation at promoter sequences leads to silencing of certain critical genes, including the tumor suppressors, thus contributing to cancer development $(3,4)$. A number of studies have focused extensively on

Correspondence to: Dr Vo Thi Thuong Lan, Faculty of Biology and Genomics Unit, Key Laboratory of Enzyme and Protein Technology, Hanoi University of Science, 334 Nguyen Trai, Thanh Xuan, Hanoi, Vietnam

E-mail: vothithuonglan@hus.edu.vn

Key words: methylation-specific polymerase chain reaction, breast cancer 1 , estrogen receptor $\alpha$, breast cancer the identification of DNA methylation patterns as biomarkers for diagnosing cancer (5-7).

A global change in DNA methylation on a genome-wide scale is able to be analyzed by DNA microarrays and high-throughput DNA sequencing, which may not be accessible to a number of institutions, particularly those in developing countries $(8,9)$. Additionally, DNA methylation at local genes may be analyzed by methods based on the PCR approach, which is routinely used in every laboratory that works with DNA (10). The majority of the PCR-based methods use genomic DNA templates that have been treated with sodium bisulfite. This chemical converts unmethylated cytosine, but not methylated cytosine, to uracil residues (11). Specific primers were designed on the basis of sequences that contain an adequate number of $\mathrm{CpG}$ islands, thus the primers distinguish methylated from unmethylated templates (12). The methylation-specific PCR (MSP) is suitable and sensitive for the detection of the $\mathrm{CpG}$ methylation status at any $\mathrm{CpG}$ islands (10). Since the MSP primer sets are specifically designed for the DNA whose composition was changed following bisulfite conversion, a trace of unmodified DNA (native DNA), due to uncompleted conversion in principle, is not amplified during the PCR reactions $(12,13)$. Thereby, the majority of the control tests (positive or negative controls) that are used to validate the MSP results for the DNA methylation patterns in different types of cancers have used only bisulfite-treated DNA and not untreated DNA extracted from different cell lines (cancer or non-cancer) or from patient's specimens (14).

In the present study, the false-positive effect caused by a trace of unmodified DNA on the MSP results was reported, using previously published primer sets to identify the methylation of the breast cancer $1(B R C A l)$ and estrogen receptor $(E R)$ genes in Vietnamese females with breast cancer. New primer sets and the set-up of additional standard controls for eliminating false-positive results were designed in order to improve the accurate positivity of the MSP method.

\section{Materials and methods}

Tissue samples. A total of 60 specimens of primary breast cancer were collected from patients undergoing surgical resection at the Department of Pathology, National Cancer 
Table I. MSP primers for analysis of $B R C A 1$ and $E R$ gene methylation.

\begin{tabular}{|c|c|c|c|c|}
\hline Gene name & Primers & Sequence $\left(5^{\prime}-3^{\prime}\right)$ & Size, bp & First author (ref.) \\
\hline \multirow[t]{12}{*}{$B R C A 1$} & BRCA-F & TCGTGGTAACGGAAAAGCGC & 75 & Esteller et al (15) \\
\hline & BRCA-R & AAATCTCAACGAACTCACGCCG & & \\
\hline & BRCA-Un F & TTGGTTTTTGTGGTAATGGAAAAGTG & 86 & Esteller et al (15) \\
\hline & BRCA-Un R & CAAAAAATCTCAACAAACTCACACCA & & \\
\hline & BM-F & GGGTAGATTGGGTGGTTAATT & Round 1: 200 & Present study \\
\hline & BRCA-R & AAATCTCAACGAACTCACGCCG & & \\
\hline & BM-F & GGGTAGATTGGGTGGTTAATT & Round 2: 195 & Present study \\
\hline & BM-R & TACACGAACTCACGCCGCGCAA & & \\
\hline & BU-F & TTAATTTAGAGTTTTGAGAGAT & Round 1: 191 & Present study \\
\hline & BRCA-Un R & CAAAAAATCTCAACAAACTCACACCA & & \\
\hline & BRCA-Un F & TTGGTTTTTGTGGTAATGGAAAAGTG & Round 2: 76 & Present study \\
\hline & BU-R & CAACAAACTCACACCACACAA & & \\
\hline \multirow[t]{10}{*}{$E R$} & ER4-F & CGAGTTGGAGTTTTTGAATCGTTC & 151 & Lapidus et al (16) \\
\hline & ER4-R & CTACGCGTTAACGACGACCG & & \\
\hline & ER4-Un F & ATGAGTTGGAGTTTTTGAATTGTTT & 158 & Lapidus et al (16) \\
\hline & ER4-Un R & ATAAACCTACACATTAACAACAACCA & & \\
\hline & EM-F & GATACGGTTTGTATTTTGTTCG & 247 & Present study \\
\hline & ER4-R & CTACGCGTTAACGACGACCG & & \\
\hline & EU4-F & GTGGGGATATGGTTTGTATTTTGTTTG & Round 1: 258 & Present study \\
\hline & ER4-Un R & ATAAACCTACACATTAACAACAACCA & & \\
\hline & ER4-Un F & ATGAGTTGGAGTTTTTGAATTGTTT & Round 2: 154 & Present study \\
\hline & EU4-R & ACСТАСАСАТТАACAACAACCACAACA & & \\
\hline
\end{tabular}

BU and EU indicated the primers specific to unmethylated targets. BM and EM indicated the primers specific to methylated targets. F, forward; $\mathrm{R}$, reverse; MSP, methylation-specific PCR; BRCA1, breast cancer 1; ER, estrogen receptor.

Hospital K, Hanoi, the largest cancer hospital in Vietnam. Informed consent was obtained from patients in written form (ICF-ATF-FP-005-VN), and the study was approved by the guidelines of the local ethical committee in Vietnam (2205/QĐ-KHCN; Vietnam National University, Hanoi, Vietnam).

Genomic DNA extraction and bisulfite modification. Genomic DNA was extracted using a QIAamp DNA Mini kit (Qiagen, Valencia, CA, USA) and treated with sodium bisulfite using an EpiTect Bisulfite kit (Qiagen). During the modification, the unmethylated cytosines of the genomic DNA were converted to uracils, but the methylated cytosines remained unchanged (11). PCR that used $\beta$-globin-F/R primer for the native DNA and Un-globin-F, -R and -R1 for treated DNA (Fig. 1) was performed to determine the efficiency of bisulfite conversion.

$M S P$. The methylation status of BRCAl and $E R$ was evaluated using two primer sets for the MSP. The first set included $B R C A I$ and $E R$ primers that were originally designed and reported by Esteller et al (15) and Lapidus et al (16), respectively. The second set included new primers that were designed using the free online tool from MethPrimer (http://www.urogene.org/methprimer/index1.html). The primer sequences and amplicon lengths are shown in Table I. PCR amplification with the first primer set was performed as described previously $(15,16)$. Bisulfite-treated DNA was subjected to a single round of PCR with the new EM-F and ER4-R ER primers. Two rounds of PCR, the first round with the BM-F/BRCA-R and the second round with BM-F/BM-R primers, were performed to detect $B R C A 1$ methylation. The $25 \mu \mathrm{l}$ of the PCR reaction contained $0.3 \mu \mathrm{mol} / 1$ primers, $100 \mu \mathrm{mol} / 1 \mathrm{dNTPs}, 2.0 \mathrm{U}$ JumpStart Taq polymerase (Sigma-Aldrich, St. Louis, MO, USA) and 1-2 $\mu$ l of bisulfitetreated DNA. The PCR conditions were follows: $94^{\circ} \mathrm{C}$ for $1 \mathrm{~min}, 40$ cycles of $\left(94^{\circ} \mathrm{C}\right.$ for $30 \mathrm{sec}, 65^{\circ} \mathrm{C}$ for $10 \mathrm{sec}$ and $72^{\circ} \mathrm{C}$ for $10 \mathrm{sec}$ ), and $72^{\circ} \mathrm{C}$ for $5 \mathrm{~min}$. The second $25 \mu 1$ nested PCR reaction contained $1 \mu \mathrm{l}$ of the first PCR product and was performed with the conditions as follows: $94^{\circ} \mathrm{C}$ for $1 \mathrm{~min}$, 40 cycles of $\left(94^{\circ} \mathrm{C}\right.$ for $30 \mathrm{sec}, 68^{\circ} \mathrm{C}$ for $10 \mathrm{sec}$ and $72^{\circ} \mathrm{C}$ for $10 \mathrm{sec}$ ) and $72^{\circ} \mathrm{C}$ for $5 \mathrm{~min}$. Two rounds of PCR were performed with the new primer sets specific to unmethylated $B R C A 1$ and $E R$. The PCR products were subjected to electrophoresis on a $12 \%$ polyacrylamide gel. All the PCR reactions were replicated at least three times.

DNA that was extracted from the lymphocytes of the healthy volunteers and then treated with bisulfite was used as a positive control for $B R C A 1$ and $E R$ unmethylation. A mixture of plasmid DNA containing methylated $B R C A l$ or $E R$ sequences and DNA extracted from normal lymphocytes was used as a positive control for BRCAl and ER methylation. Water without a DNA template was included in each PCR reaction as a control for any contamination. The meth- 

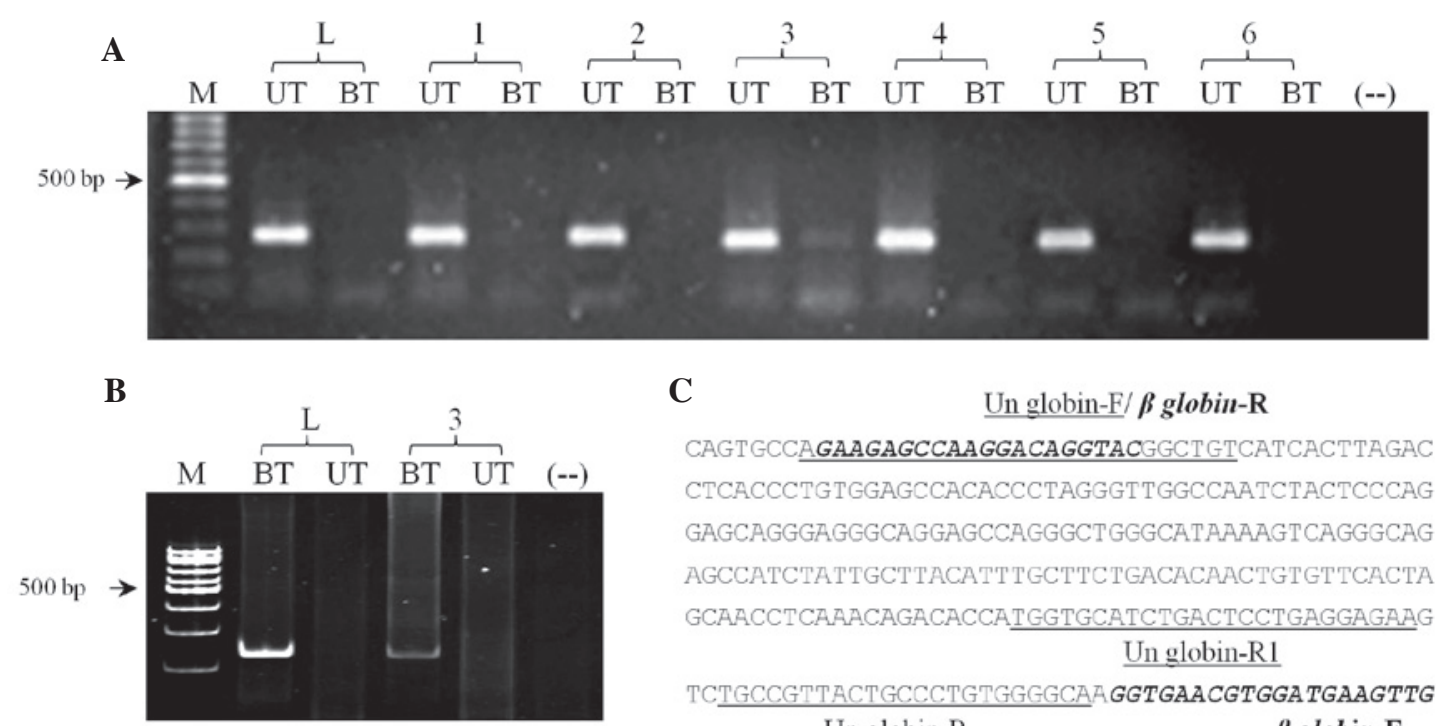

$\mathbf{C}$

CAGTGCCAGAAGAGCCAAGGACAGGTACGGCTGTCATCACTTAGAC CTCACCCTGTGGAGCCACACCCTAGGGTTGGCCAATCTACTCCCAG GAGCAGGGAGGGCAGGAGCCAGGGCTGGGCATAAAAGTCAGGGCAG AGCCATCTATTGCTTACATTTGCTTCTGACACAACTGTGTTCACTA GCAACCTCAAACAGACACCATGGTGCATCTGACTCCTGAGGAGAAG Un globin-R1

TCTGCCGMTACT GCCCTGTGGGGCA GGTGAACGTGGATGAAGTTG $\underline{\text { Un globin-R }}$

B globin-F

Figure 1. Representative result for efficiency of bisulfite conversion. (A) Detection of a band of 268 bp amplified by the $\beta$-globin primer set. (B) Detection of a band of $244 \mathrm{bp}$ amplified by the nested Un globin primer set. (C) Nucleotide sequence of the 5 ' region of $\beta$-globin gene (accession no. U01317.1) and primer location. F, forward; R, reverse; UT, untreated DNA; BT, bisulfite-treated DNA; L, lymphocytes of the healthy volunteer; 1-6, breast cancer specimens; M, 100-bp DNA ladder; (--), negative control without DNA template.

A

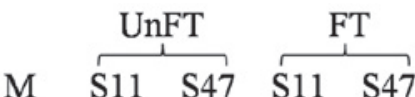

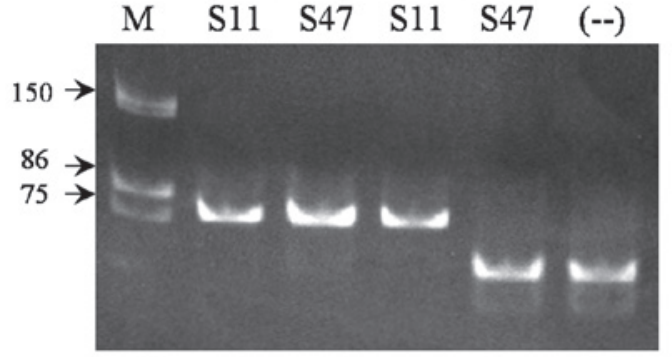

B

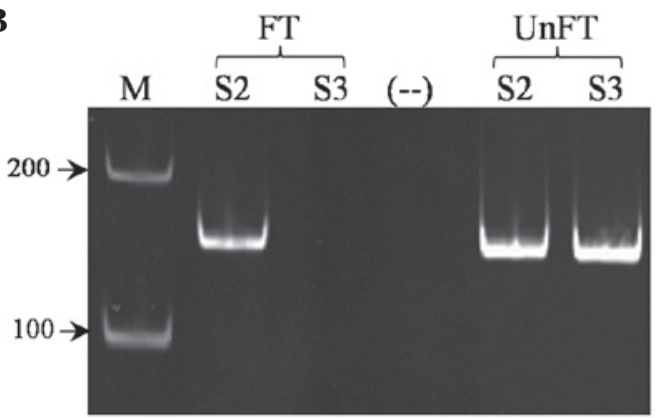

C

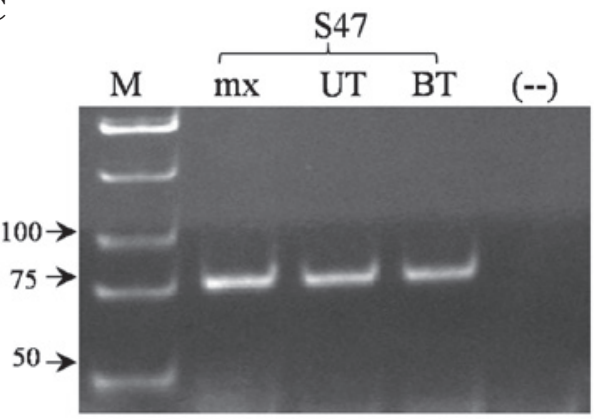

D

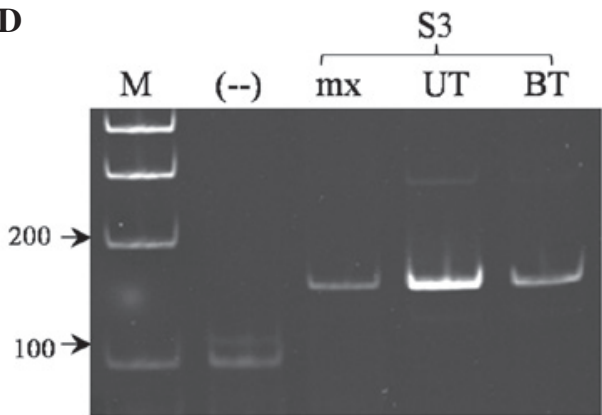

Figure 2. Representative analysis of MSP products amplified by (A and B) the first primer sets of BRCAl and (C and D) ER. UnFT, incompletely converted DNA; FT, completely converted DNA; mx, mixture of untreated and completely converted DNA; UT, untreated DNA; BT, bisulfite-treated DNA without verifying the efficiency of full conversion; S1, S3, S11 and S47, different samples of breast cancer tissue; M, DNA ladder; (--), negative control without DNA templates; MSP, methylation-specific PCR; BRCA1, breast cancer 1; ER, estrogen receptor.

ylation status was confirmed by sequencing the cloned MSP products for a subset of samples from each assay.

\section{Results}

The full conversion of genomic DNA that was extracted from the primary breast cancer specimens was verified by PCR with a $\beta$-globin primer set (Fig. 1). Using primers designed from native DNA sequences, the majority of the PCR products were revealed to be amplified from untreated and not bisulfite-converted DNA (Fig. 1A). By contrast, the PCR products amplified by primers designed for unmethylated globin sequences were detected from the bisulfite-treated DNA, but not the native DNA (Fig. 1B). Negligible PCR products were amplified from several treated DNA samples possibly due to an incomplete conversion. Incompletely and completely 
A

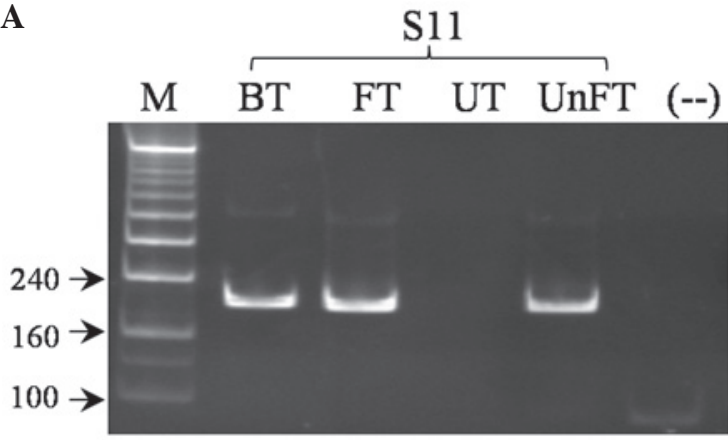

B

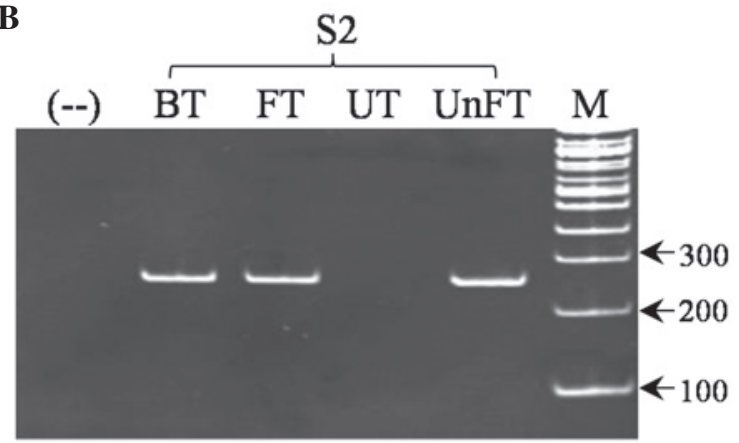

Figure 3. Representative analysis of MSP products amplified by the new primer sets of (A) BRCA1 and (B) ER. BT, bisulfite-treated DNA without verifying the efficiency of full conversion; FT, completely converted DNA; UT, untreated DNA; UnFT, incompletely converted DNA; S2 and S11, breast cancer tissue samples; M, DNA ladder; (--), negative control without DNA templates; MSP, methylation-specific PCR; BRCA1, breast cancer 1; ER, estrogen receptor.

A

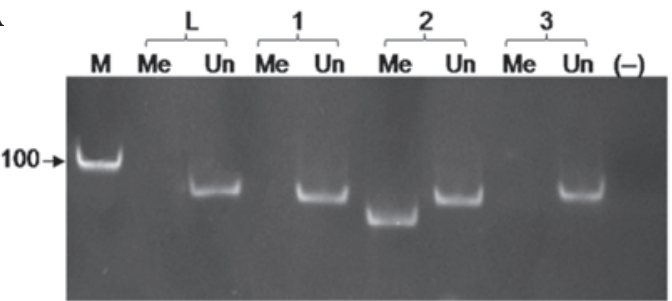

B

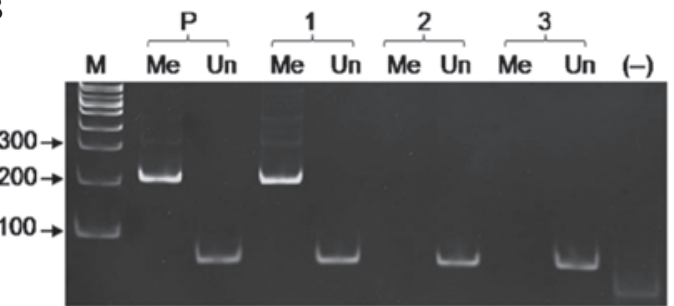

C

$\underline{B M-F}$

GGGGCAGACTGGGTGGCCAATCCAGAGCCCCGAGAGACGCT TGGCTCTTTCTGTCCCTCCCATCCTCTGATTGTACCTTGAT TTCGTATTCTGAGAGGCTGCTGCTTAGCGGTAGCCCCTTGG TTTCCGTGGCAACGGAAAAGCGCGGGATTACAGATAAATT BRCA-F

\section{AAAACTGCGACTGCGCGGCGTGAGCTCGCTGAGACTTCCT} BM-R $\quad B R C A-R$
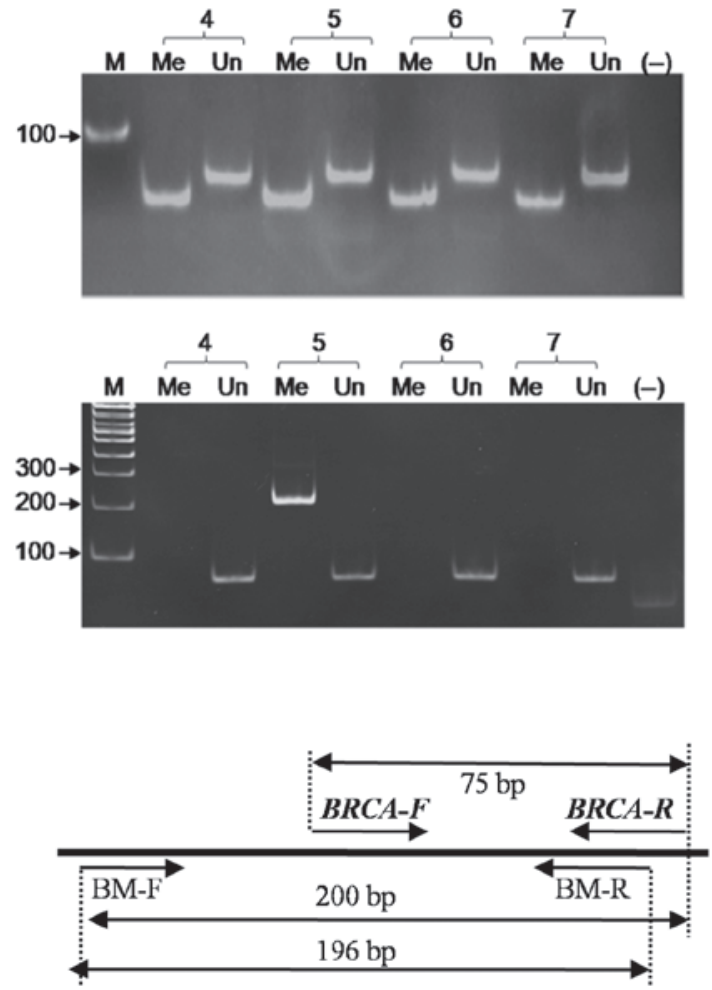

Figure 4. Representative analysis of $B R C A 1$-MSP products amplified by (A) the first primer set and (B) the second primer set without verifying the efficiency of full conversion of the DNA templates. 1-7, breast cancer samples; Me, the presence of BRCA1 methylation; Un, the presence of BRCA1 unmethylation; $\mathrm{L}$, lymphocytes of the healthy volunteer; P, plasmid DNA, including BRCA1 methylated sequence mixed with DNA extracted from lymphocytes of the healthy volunteer; M, DNA ladder; (--), negative control without DNA template. (C) The nucleotide sequence of the 5' region of BRCA1 (accession no. NG-005905.2) and the location of the BRCA1-MSP primers listed in Table I. BM indicated the primers specific to methylated BRCA1. BRCA1, breast cancer ; MSP, methylation-specific PCR; F, forward; R, reverse.

converted DNA were applied separately to MSP with the first $B R C A l$ and $E R$ primer sets. Unexpectedly, in several samples, methylation of $B R C A I$ and $E R$ was detected from the incompletely modified DNA and not from the fully modified DNA (Fig. 2A and C). It was likely that the primer sets specifically designed for methylated $B R C A I$ and $E R$ wrongly amplified the native DNA template that was not modified, and this template remained through the bisulfite reaction.

To confirm this hypothesis, untreated genomic (native) DNA was subjected to MSP with the first BRCAl and $E R$ primer sets, which were appropriate for detecting methylation (Fig. 2B and D). PCR products were amplified from untreated genomic DNA and from a mixture of untreated genomic DNA and completely modified DNA. In addition, the PCR products were also amplified from untreated DNA by using the primer sets specifically designed for unmethylated $E R$ and BRCAl (data not shown). The analysis indicated a false-positive result that was due to a trace of native DNA not being converted, but being retained through bisulfite treatment.

Based on the primer design strategies for the MSP method, new primers for BRCAl and $E R$ were designed. A number of 
A
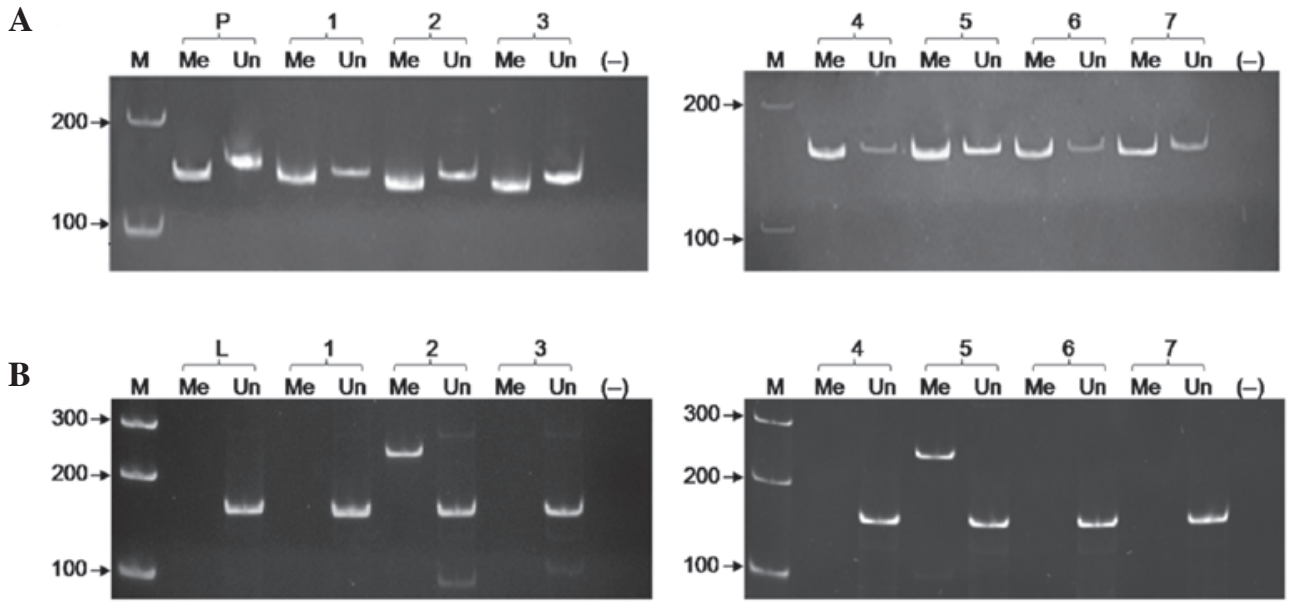

\section{C}

EM-F
GACACGGTCTGCACCCTGCCCGCGGCCACGGACCATGACCATGAC
CCTCCACACCAAAGCATCTGGGATGGCCCTACTGCATCAGATCCA
AGGGAACGAGCTGGAGCCCCTGAACCGTCCGCAGCTCAAGATCCC
ER4-F
CCTGGAGCGGCCCCTGGGCGAGGTTACCTGGACAGCAGCAAGCC
CGCCGTGTACAACTACCCCGAGGCGCCGCCTACGAGTTCAACGC
CGCGGCCGCCGCCAACGCGCAG
ER $\mathbf{R}-\boldsymbol{R}$

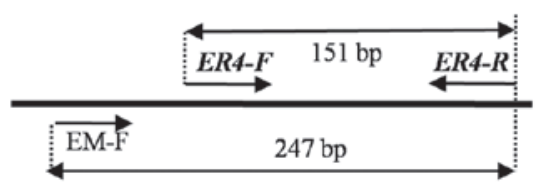

Figure 5. Representative analysis of $E R$-MSP products amplified by (A) the first primer set and (B) the second primer set without verifying the efficiency of the full conversion of the templates. 1-7, breast cancer samples; Me, the presence of $E R$ methylation; Un, the presence of $E R$ demethylation; L, lymphocytes of the healthy volunteer; P, plasmid DNA, including $E R$ methylated sequence mixed with DNA extracted from lymphocytes of the healthy volunteer; M, DNA ladder $100 \mathrm{bp}$; (--), negative control without DNA template. (C) The nucleotide sequence of the 5 ' region of $E R$ (accession no. AL356311.6) and the location of the ER-MSP primers listed in Table I. EM indicated the primers specific to methylated $E R$. ER, estrogen receptor; MSP, methylation-specific polymerase chain reaction.

these primers were used in combination with the published primers (Table I). PCR was performed in which either untreated or bisulfite-treated genomic DNA was used as a template. The methylation of BRCAl and $E R$ was detected from the treated DNA, but not from the untreated DNA (Fig. 3), and unmethylation of BRCAl and $E R$ was also detected from the treated DNA, but not from the untreated DNA (data not shown). This indicates the precision and specificity of the new primer sets in distinguishing methylated from unmethylated and untreated sequences.

Genomic DNA extracted from 60 breast cancer specimens was treated with bisulfite and subjected directly to MSP without verifying the full conversion following treatment. The number of cases of methylated BRCAl and ER detected by the first primer set was $25 / 60$ and $47 / 60$, respectively and that detected by the second primer set was $7 / 60$ and 21/60, respectively (Figs. 4 and 5). When treated DNA whose full conversion was examined through PCR with the $\beta$-globin primers and with the new primers were used as templates for the two primer sets, the same result (7/60 and 21/60 methylated DNA, respectively) was obtained. Therefore, incompletely converted DNA resulted in 18 and 26 cases of false-positive methylation of $B R C A I$ and $E R$, respectively. Unmethylation of $B R C A 1$ and $E R$, was detected in the DNA of all 60 breast cancer patients.

False priming events of the first primer set were confirmed by cloning and sequencing the MSP products that were amplified from untreated DNA templates (data not shown). The nucleotide sequences amplified by the first primer set specific to $B R C A 1$ and $E R$ methylation were revealed to be identical to native sequences. In addition, three representatives of the MSP products amplified from either incompletely converted or fully converted DNA by the second BRCAI and $E R$ primer set were also cloned and subsequently sequenced. The nucleotide sequences revealed that all cytosine residues were converted to thymidines in BRCAl and $E R$ unmethylated products, and that all cytosines in the $\mathrm{CpG}$ sites remained as cytosines. The cytosines that were not in the $\mathrm{CpG}$ sites were converted to thymidines in the BRCAl and ER methylated products.

\section{Discussion}

Among the different types of markers that are capable of distinguishing tumors from normal tissue, the DNA methylation marker has become the most attractive due to its sensitivity, specificity and applicability to a variety of clinical specimens $(12,17)$. MSP is the most widely used method for the sensitive detection of DNA methylation (10). As this method requires common equipment only, MSP may allow every laboratory to approach and develop the DNA methylation marker for the purpose of diagnosis and prognosis of cancers (5-7).

Using the MSP method, aberrant methylation at the 5 'region has been reported on a number of genes in different types of cancer (18-20). The MSP result for one gene is dependent on the analyzed sequence of the 5 ' region and the type of cancer. Thus, for a specific type of cancer, utilization of 
the same panel of targeted genes and of the same region of the gene for analysis of DNA methylation should be validated and reproduced to increase the accuracy of DNA methylation markers in clinical applications (14).

The BRCAl and ER genes are the targets of aberrant DNA methylation in breast tumors; thus, they are a subject being studied extensively (21-24). The BRCAl gene encodes a multifunctional protein that is involved in DNA repair, cell cycle control and chromatin remodeling (25). The ER has a central role in an important signaling pathway of mammary cells (26). The primers that were first designed for analysis of BRCAl (15) and ER methylation (16) by the MSP method have been subsequently applied to numerous studies to detect the $B R C A 1$ and $E R$ methylation status in different types of cancer, including breast cancer (27-30). In the present study, these primers were also employed for the analysis of the BRCAI and $E R$ methylation status in females with breast cancer, using untreated and treated DNA as templates. The results shown in Fig. 2 revealed that methylation of $B R C A 1$ and $E R$ was detected in both types of DNA, and this indicates that these primers did not discriminate between methylated and unconverted sequences. The sequencing data confirmed that the first set of $B R C A I$ and $E R$ primers amplified the unconverted sequences whose cytosine residues were retained. In replicated experiments, the co-amplification of untreated sequences by only the first primer set was confirmed by MSP and sequencing (data not shown). The number of cases of methylated BRCA1 and $E R$ detected by the first primer set was $25 / 60$ (41.7\%) and $47 / 60(78.3 \%)$, respectively, and that detected by the second primer set was $7 / 60(11.7 \%)$ and 21/60 (35.0\%), respectively. A big difference in the methylation levels (4-fold in BRCA1 methylation and 2-fold in $E R$ methylation) was revealed between the two primer sets. A significant difference in the DNA methylation of the same gene(s) in one cancer type, for example, eight-fold difference (5-40\%) in the BRCA1 methylation in breast cancer was reviewed by a number of different laboratories, thus barriers in the performance of DNA methylation as cancer biomarkers have been observed $(14,31)$. The results of the present study indicate that in numerous previous studies, the significant difference in gene methylation analyzed by the MSP in general, and in particular for BRCAI and $E R$ methylation in breast cancer, was an overestimation that resulted from the shortcomings of control tests for the accuracy of MSP primers specific to the treated sequences only. An overestimation may be prevented by the full conversion of the DNA template, which may be verified through PCR with housekeeping gene primers (Fig. 1) (32). However, such test controls are required for each bisulfite-treated DNA template; thus, they are laborious. The present study provided a simple control test that eliminated the overestimation without verifying the full conversion. Since the precision of the MSP primers was affirmed through PCR with untreated DNA, a trace of uncompleted treated DNA was not inferred from the MSP results (Fig. 3). Indeed, in the present study, the BRCA1 and ER methylation levels detected by the new primers, BM-F/BRCA-R and BM-F/BM-R, and EM-F and ER4-R (Table I) were four- and two-fold less than that detected by the set of primers reported by Esteller et al (15) and Lapidus et al (16), respectively, and much less than that detected by the first set of primers from previous studies
(26-56\%), in which no control tests for the full conversion through PCR were reported $(22,33)$. Thus, an accurate evaluation of the MSP primer specificity to treated sequences only must avoid false-positive results.

MSP is a highly sensitive method; thus, different approaches developed from or in combination with MSP, including BS-MSP (Bisulfite conversion-Specific and Methylation-Specific PCR), MEP (Methylation Enrichment Pyrosequencing) and ConLight MSP (MSP, Conversionspecific hybridization and MethyLight), for analysis of DNA methylation have been reported (34-36). However, the precision of MSP primers specific to methylated sequences only has not been verified in these methods to date. Previous results have demonstrated that incomplete conversion may typically be in the order of $2 \%$, even when a commercial kit is used (37). Considering the data of the present study, it is proposed that all studies based on the MSP approach should incorporate more steps in the control of the specificity and precision of primers. By using untreated sequences as the template for amplification with MSP primer sets, overestimation of DNA methylation may be avoided. MSP is simple, highly sensitive, extremely cost-effective and does not require any special equipment; thus, MSP is the most widely used method for the analysis of DNA methylation in the majority of laboratories, particularly in those that are moderately equipped in developing countries. The present study contributed to the standardization of the MSP method and the validation of its precision. The study may also promote the fast progression of the DNA methylation marker towards its clinical application.

\section{Acknowledgements}

The present study was supported by the Ministry of Science and Technology, Vietnam (nos. NAFOSTED106.06/2010.20 and KC.04.05/11-15).

\section{References}

1. Laird PW: The power and the promise of DNA methylation markers. Nat Rev Cancer 3: 253-266, 2003.

2. Dworkin AM, Huang TH and Toland AE: Epigenetic alterations in the breast: Implications for breast cancer detection, prognosis and treatment. Semin Cancer Biol 19: 165-171, 2009.

3. Patel A, Groopman JD and Umar A: DNA methylation as a cancer-specific biomarker: from molecules to populations. Ann NY Acad Sci 983: 286-297, 2003.

4. Brooks J, Cairns P and Zeleniuch-Jacquotte A: Promoter methylation and the detection of breast cancer. Cancer Causes Control 20: 1539-1550, 2009.

5. Baylin SB and Ohm JE: Epigenetic gene silencing in cancer - a mechanism for early oncogenic pathway addiction? Nat Rev Cancer 6: 107-116, 2006.

6. Visvanathan K, Sukumar S and Davidson NE: Epigenetic biomarkers and breast cancer: cause for optimism. Clin Cancer Res 12: 6591-6593, 2006.

7. Heyn $\mathrm{H}$ and Esteller M: DNA methylation profiling in the clinic: applications and challenges. Nat Rev Genet 13: 679-692, 2012.

8. Andrews J, Kennette W, Pilon J, Hodgson A, Tuck AB Chambers AF and Rodenhiser DI: Multi-platform whole-genome microarray analyses refine the epigenetic signature of breast cancer metastasis with gene expression and copy number. PLoS One 5: e8665, 2010.

9. Feng S, Rubbi L, Jacobsen SE and Pellegrini M: Determining DNA methylation profiles using sequencing. Methods Mol Biol 733: 223-238, 2011 
10. Kristensen LS and Hansen LL: PCR-based methods for detecting single-locus DNA methylation biomarkers in cancer diagnostics, prognostics, and response to treatment. Clin Chem 55: 1471-1483, 2009.

11. Clark SJ, Harrison J, Paul CL and Frommer M: High sensitivity mapping of methylated cytosines. Nucleic Acids Res 22 2990-2997, 1994.

12. Herman JG, Graff JR, Myöhänen S, Nelkin BD and Baylin SB: Methylation-specific PCR: a novel PCR assay for methylation status of CpG islands. Proc Natl Acad Sci USA 93: 9821-9826, 1996.

13. Hughes S and Jones JL: The use of multiple displacement amplified DNA as a control for methylation specific PCR pyrosequencing, bisulfite sequencing and methylation-sensitive restriction enzyme PCR. BMC Mol Biol 8: 91, 2007.

14. Kagan J, Srivastava S, Barker PE, Belinsky SA and Cairns P: Towards clinical application of methylated DNA sequences as cancer biomarkers: A joint NCI's EDRN and NIST workshop on standards, methods, assays, reagents and tools. Cancer Res 67 4545-4549, 2007.

15. Esteller M, Silva JM, Dominguez G, et al: Promoter hypermethylation and BRCA1 inactivation in sporadic breast and ovarian tumors. J Natl Cancer Inst 92: 564-569, 2000.

16. Lapidus RG, Nass SJ, Butash KA, et al: Mapping of ER gene $\mathrm{CpG}$ island methylation by methylation-specific polymerase chain reaction. Cancer Res 58: 2515-2519, 1998.

17. Cottrell SE and Laird PW: Sensitive detection of DNA methylation. Ann NY Acad Sci 983: 120-130, 2003

18. Rabiau N, Thiam MO, Satih S, et al: Methylation analysis of BRCA1, RASSF1, GSTP1 and EPHB2 promoters in prostate biopsies according to different degrees of malignancy. In Vivo 23: 387-391, 2009.

19. Yamashita M, Toyota M, Suzuki H, et al: DNA methylation of interferon regulatory factors in gastric cancer and noncancerous gastric mucosae. Cancer Sci 101: 1708-1716, 2010.

20. Chou JL, Su HY, Chen LY, et al: Promoter hypermethylation of FBXO32, a novel TGF-beta/SMAD4 target gene and tumor suppressor, is associated with poor prognosis in human ovarian cancer. Lab Invest 90: 414-425, 2010.

21. Hansmann T, Pliushch G, Leubner M, et al: Constitutive promoter methylation of BRCA1 and RAD51C in patients with familial ovarian cancer and early-onset sporadic breast cancer. Hum Mol Genet 21: 4669-4679, 2012.

22. Hsu NC, Huang YF, Yokoyama KK, Chu PY, Chen FM and Hou MF: Methylation of BRCA1 promoter region is associated with unfavorable prognosis in women with early-stage breast cancer. PLoS One 8: e56256, 2013.

23. Archey WB, McEachern KA, Robson M, et al: Increased CpG methylation of the estrogen receptor gene in BRCA1-linked estrogen receptor-negative breast cancers. Oncogene 21: 7034-7041, 2002.
24. Mann M, Cortez V and Vadlamudi RK: Epigenetics of estrogen receptor signaling: Role in hormonal cancer progression and therapy. Cancers (Basel) 3: 1691-1707, 2011.

25. Marquis ST, Rajan JV, Wynshaw-Boris A, et al: The developmental pattern of BRCA1 expression implies a role in differentiation of the breast and other tissues. Nat Genet 11: 17-26, 1995.

26. Hayashi S, Niwa T and Yamaguchi Y: Estrogen signaling pathway and its imaging in human breast cancer. Cancer Sci 100: 1773-1778, 2009.

27. Tapia T, Smalley SV, Kohen P, et al: Promoter hypermethylation of BRCA1 correlates with absence of expression in hereditary breast cancer tumors. Epigenetics 3: 157-163, 2008.

28. Wang YQ, Zhang JR, Li SD, He YY, Yang YX, Liu XL and Wan XP: Aberrant methylation of breast and ovarian cancer susceptibility gene 1 in chemosensitive human ovarian cancer cells does not involve the phosphatidylinositol 3'-kinase-Akt pathway. Cancer Sci 101: 1618-1623, 2010.

29. Harder J, Engelstaedter V, Usadel H, et al: CpG-island methylation of the ER promoter in colorectal cancer: analysis of micrometastases in lymph nodes from UICC stage I and II patients. Br J Cancer 100: 360-365, 2009.

30. Wei M, Xu J, Dignam J, et al: Estrogen receptor alpha, BRCA1, and FANCF promoter methylation occur in distinct subsets of sporadic breast cancers. Breast Cancer Res Treat 111: 113-120, 2008.

31. Senturk E, Cohen S, Dottino PR and Martignetti JA: A critical re-appraisal of BRCA1 methylation studies in ovarian cancer. Gynecol Oncol 119: 376-383, 2010.

32. Wilcox CB, Baysal BE, Gallion HH, Strange MA and DeLoia JA: High-resolution methylation analysis of the BRCA1 promoter in ovarian tumors. Cancer Genet Cytogenet 159: 114-122, 2005

33. Chen Y, Zhou J, Xu Y, et al: BRCA1 promoter methylation associated with poor survival in Chinese patients with sporadic breast cancer. Cancer Sci 100: 1663-1667, 2009.

34. Sasaki M, Anast J, Bassett W, Kawakami T, Sakuragi N and Dahiya R: Bisulfite conversion-specific and methylation-specific PCR: a sensitive technique for accurate evaluation of $\mathrm{CpG}$ methylation. Biochem Biophys Res Commun 309: 305-309, 2003.

35. Shaw RJ, Akufo-Tetteh EK, Risk JM, Field JK and Liloglou T: Methylation enrichment pyrosequencing: combining the specificity of MSP with validation by pyrosequencing. Nucleic Acids Res 34: e78, 2006.

36. Rand K, Qu W, Ho T, Clark SJ and Molloy P: Conversion-specific detection of DNA methylation using real-time polymerase chain reaction (ConLight-MSP) to avoid false positives. Methods 27: 114-120, 2002.

37. Warnecke PM, Stirzaker C, Song J, Grunau C, Melki JR and Clark SJ: Identification and resolution of artifacts in bisulfite sequencing. Methods 27: 101-107, 2002. 